\title{
Fabrication and Characterization of Tensile Deformation of Tin-Lead Open Cell Foams
}

\author{
A.-E. Belhadj ${ }^{a, b, *}$, M. AzzAZ ${ }^{a}$ AND S. ABUdura ${ }^{b}$ \\ ${ }^{a}$ Laboratory of Materials Science and Engineering, University of Science and Technology Houari Boumediene, \\ Bab-Ezzouar, Algiers, Algeria \\ ${ }^{b}$ Faculty of Science and Technology, University of Médéa, Algeria
}

\begin{abstract}
This study is devoted to the investigation of metallic foams based on tin-lead alloy (with $50 \%$ of tin content) by the liquid metal infiltration process. Uniaxial tensile tests were performed at room temperature in order to study mechanical properties of foams of different relative density and cell size. The samples were concurrently characterized on a microscopic scale (metallography and hardness) in order to link the morphological and mechanical characteristics of the constitutive phases.
\end{abstract}

DOI: $10.12693 /$ APhysPolA.128.615

PACS: $62.40 .+\mathrm{i}, 82.70 . \mathrm{Rr}, 62.20 . \mathrm{M}-$

\section{Introduction}

Metal foams belong to the family of cellular materials. They are light materials which may be employed in various engineering applications. Their structure consists of an assemblage of empty cells surrounded by solid walls or edges. There is a growing interest in the scientific community in this class of materials owing to their wide potential applications. The fabrication process of metallic foams is far from being a straightforward task, as it requires a comprehensive understanding of the relationship between the structure and the mechanical properties. The final mechanical properties of metal foams cannot be fully controlled because of their significant microstructural heterogeneity originated from the fabrication process $[1,2]$.

There are several methods for fabrication metal foams [3-5]. Among those who have been already commercially introduced, the Alporas $(\mathbb{B}$ process uses a precursor powder metallurgy and a foaming agent such as $\mathrm{TiH}_{2}$ [3], which is released when the precursor is heated until it reaches the semiliquid phase. Another process was implemented by Cymat [4] using continuous casting of an alloy made sufficiently viscous by the addition of ceramic particles. In this work open cell foams based on binary tin-lead alloy, prepared by infiltration process are investigated. The fabrication method is similar to that implemented by Polinski et al. [6] and by Casolco et al. [7] to obtain magnesium and zinc-aluminum foams, respectively. Typical applications of $\mathrm{Sn}-\mathrm{Pb}$ are solders (still used in spite of the lead content for high power semiconductor application). Other applications are of tribological nature. Our interest in $\mathrm{Sn}-\mathrm{Pb}$ lies primarily in the ease of fabrication by the liquid metal replication technique.

* corresponding author; e-mail: Belhadj_1@yahoo.fr
In contrast to our previous work [8], where the specimens were deformed in compression here we focused on the mechanical characterization of our samples having different relative densities in tension. For a cellular material, the mechanical properties such as the Young modulus or the stress at failure can be related to its relative density $\rho / \rho_{0}$ ( $\rho$ the density of the cellular material and $\rho_{0}$ is that of the dense material).

In order to verify the theoretical data, we conducted tensile tests on foams having various pore sizes, which enabled us to compare the stress-strain curves for various relative densities. Microscopic characterization of the samples was carried out with optical microscope. Further measurements of microhardness were performed on tin rich phase, lead rich phase and on the foam cell struts.

\section{Experimental}

The main components used in this study for making metal foams are salt, ingots of tin-lead with a tin content of $50 \%$. The latter component exhibit enhanced fluidity associated with the binary $\mathrm{Sn} 38-\mathrm{Pb} 62$ eutectic (weight \%) at approximately $180^{\circ} \mathrm{C}[9,10]$. The fabrication process consists in preparing several performs with different salt grain size. The molten metal is then poured and infiltrates the salt performs. After the solidification of alloy the salt is dissolved in water which results in a metallic foam with open cells whose structure is the negative of the perform used - this is the so-called "negative replication process". Tensile tests were performed in a MTS brand Adamel Lhomargy-DY36 device using a crosshead speed of $2 \mathrm{~mm} / \mathrm{min}$ until rupture of the sample.

For microscopic observation, the samples were sectioned, coated in resin, polished on silicon carbide disc, then diamond lapped and finished using colloidal silica. The foam morphology and the constitutive phases were investigated in a Zeiss Axiovert 450 light optical microscope.

The Vickers microhardness was measured in a Buehler Micromet 5124 tester using various loads $-5 \mathrm{~g}$ for 
hardness measurement of the phases and $10 \mathrm{~g}$ for testing of overall hardness.

Differential thermal analyses of the samples were carried out in alumina crucibles, under argon, by a DTANETZSCH $404 \mathrm{~S}$ thermal analysis apparatus. The heating and cooling rate adopted in this study was $5 \mathrm{~K} / \mathrm{min}$. The thermocouples were calibrated with temperatures of the $\gamma$-Fe $\Leftrightarrow \delta$-Fe transformation at $1392^{\circ} \mathrm{C}$ and the $\delta$ $\mathrm{Fe} \Leftrightarrow \alpha$-Fe transformation at $911^{\circ} \mathrm{C}$.

\section{Results and discussion}

\subsection{Presentation of samples}

Figure 1 shows several successfully prepared samples which were used for uniaxial tensile tests. The experimental setup used for tensile test is presented in Fig. 2.

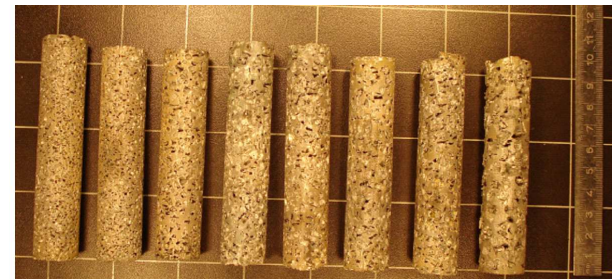

Fig. 1. Photographs of the $\mathrm{Sn} 50-\mathrm{Pb}$ tensile samples obtained by liquid metal infiltration using various salt granulometries.
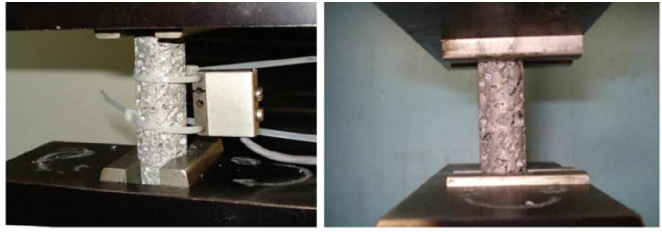

Fig. 2. Fixation of the sample between the clamps of a tensile-testing machine.

\subsection{Density measurements}

The main feature of cellular materials is their relative density: $\rho^{*} / \rho$, where $\rho^{*}$ is the density of cellular solid and $\rho$ the density of the solid which consists of. Considering the cylindrical shape of our foam, we were able to calculate their geometry density which were measured and verified by the method of three weighed. The results obtained are summarized in the Table.

TABLE

Values of the yield stresses $\sigma_{\mathrm{p}}$ corresponding to each sample and their relative densities.

\begin{tabular}{c|c|c|c|c|c}
\hline \hline Sample & $\begin{array}{c}\text { Particle } \\
\text { sizes } \\
{[\mathrm{mm}]}\end{array}$ & $\begin{array}{c}\text { Relative } \\
\text { density } \\
\rho^{*} / \rho\end{array}$ & $\begin{array}{c}\text { Yield } \\
\text { stress } \sigma_{\mathrm{p}} \\
{[\mathrm{MPa}]}\end{array}$ & $\ln \left(\sigma_{\mathrm{p}}\right)$ & $\ln \left(\rho^{*} / \rho\right)$ \\
\hline $\mathrm{A}$ & 1.60 & 0.3144 & 13.64 & 2.6130 & -1.1571 \\
$\mathrm{~B}$ & 2.00 & 0.3685 & 17.39 & 2.8559 & -0.9983 \\
$\mathrm{C}$ & 2.50 & 0.4189 & 18.90 & 2.9391 & -0.8701 \\
$\mathrm{D}$ & 3.15 & 0.3349 & 15.19 & 2.7206 & -1.0939 \\
$\mathrm{E}$ & 4.00 & 0.3291 & 14.63 & 2.6831 & -1.1114
\end{tabular}

\subsection{Stress-strain curves}

The mechanical behavior of foams has been studied as a function of the relative density of each sample. Figure 3 shows the mechanical response of sample of class B during tensile test. Figure 4 compares the stress-strain deformation curves of five samples having various pore sizes and relative density.

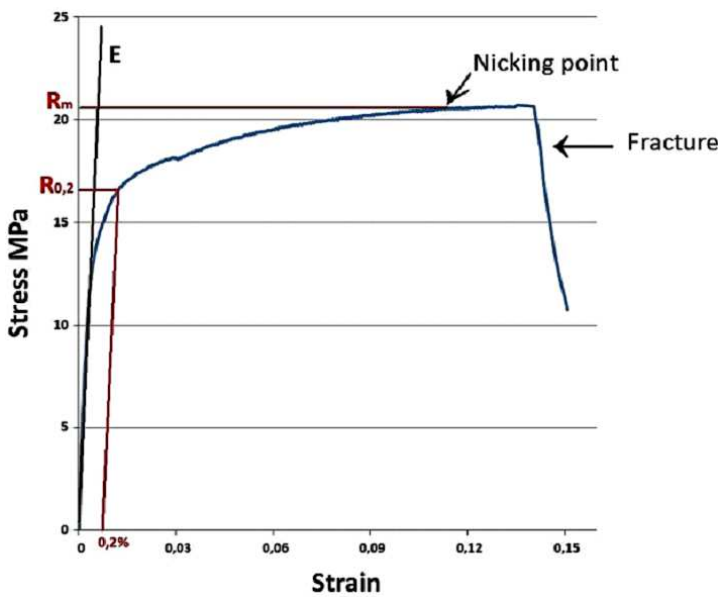

Fig. 3. Typical response curve during the tensile test on the sample B - the yield stress method calculation.

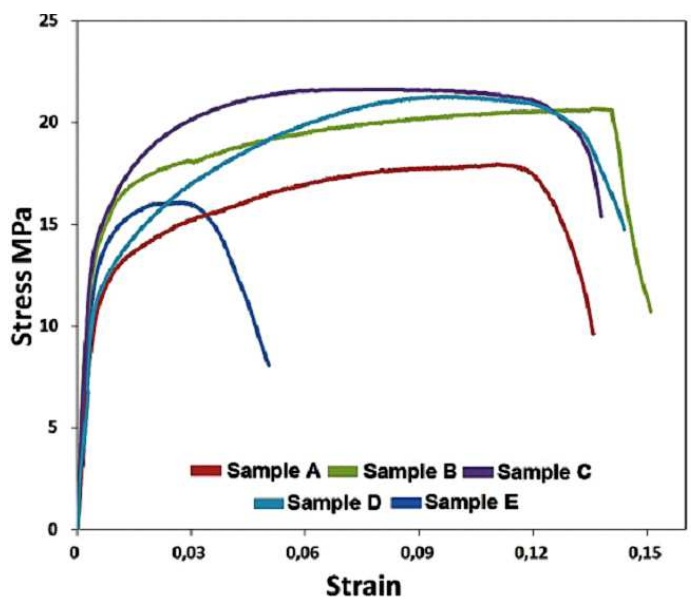

Fig. 4. Stress-strain curves obtained during tensile tests on five foam $\mathrm{Sn} 50-\mathrm{Pb}$ samples.

We note that the shape of tensile curves depends on the relative density of each sample.

\subsection{Relation stress-relative density}

The values of $\sigma_{\mathrm{p}}$ and relative densities corresponding to standard samples of their class size are listed in the Table. The yield stress is even larger than the relative density is high.

The bilogarithmic representation shows a linear relation of slope $n$ equal to 1.14 , while the equation of Gibson and Ashby [11] suggested a 3/2 exponent (see Eq. (1)) and 1.99 in compression [8]. The product $\sigma_{0} C$ is about $52 \mathrm{MPa}$, which is compatible with a 
value of $\sigma_{0}$ of $41 \mathrm{MPa}$ (tensile strength) for the massive alloy of same composition in the literature [12], and constant $C$ would then be equal to 1.26 instead of 0.3 according to Gibson and Ashby.

\subsection{Microscopic studies}

Phases present at equilibrium at a given temperature and their respective proportions can be deduced from the equilibrium phase diagram. The Sn50-Pb50 alloy consists two phases, a lead rich and a tin rich phase, respectively (Figs. 5-8). The tin rich phase results from the invariant binary eutectic Liq. $\rightarrow(\mathrm{Sn})+(\mathrm{Pb})$ for $(38.1 \% \mathrm{~Pb}$ and $183^{\circ} \mathrm{C}$ ) [1]. The spacing of the phases is $\approx 10 \mu \mathrm{m}$. The pro-eutectic microstructure for lead is characterized by a secondary dendrite spacing of almost $20 \mu \mathrm{m}$, which should indicate speeds of cooling of about $1 \mathrm{~K} / \mathrm{s}$ [13].

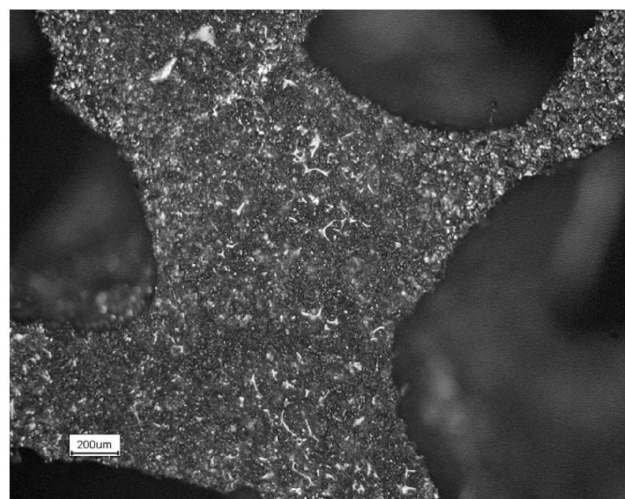

Fig. 5. Micrograph of the sample A fabricated by the liquid metal replication technique.

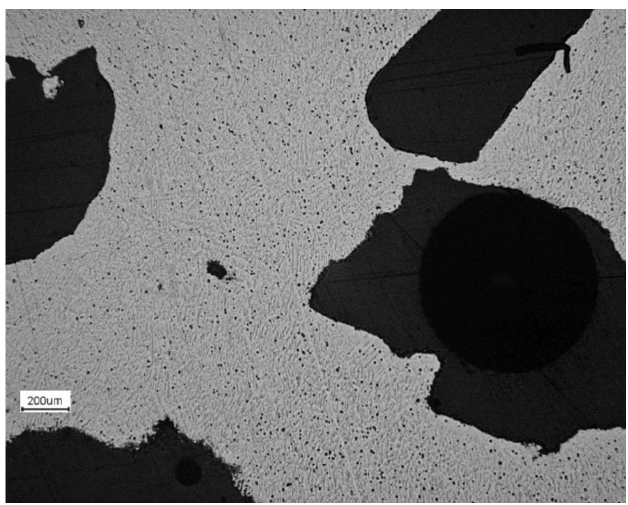

Fig. 6. As in Fig. 5, but for sample B.

\subsection{Hardness studies}

It is obvious that interdendritic spaces rich in tin are harder than the dendritic phase rich in lead.

In other words, the white phase has hardness higher than the gray one. The choice of loads taken to measure the hardness of the individual phases is dictated by the size of phases, $10 \mu \mathrm{m}$ (maximum). For the measurement of the overall hardness (gray phase and white

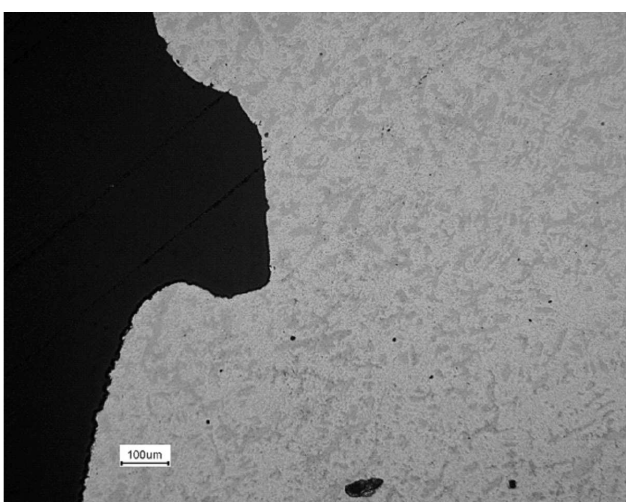

Fig. 7. As in Fig. 5, but for sample C.

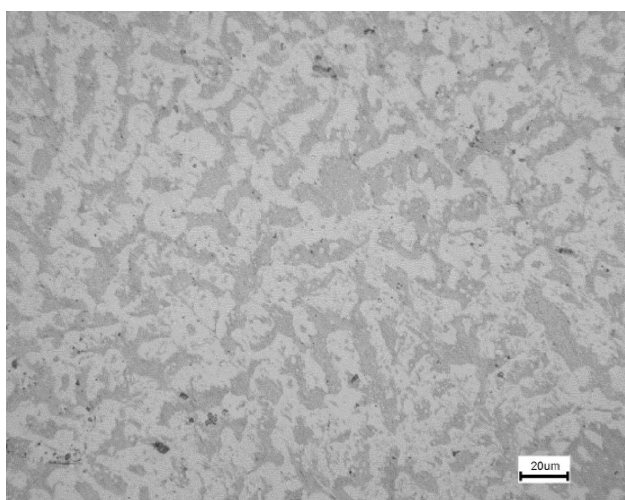

Fig. 8. As in Fig. 5 - detail of Fig. 7 .

phase), we chose a load which corresponds to an imprint diagonal between 40 and $45 \mu \mathrm{m}$ which makes it possible to characterize the "homogenized" material. It is obvious that scatter of hardness values is larger within the gray phase most probably owing to the presence of tin precipitations in lead (see Fig. 9). The hardness of the alloy is about $10 \mathrm{HV}$ which corresponds to a flow stress of approximately $30 \mathrm{MPa}$, which is very close to the value $\sigma_{0}$ which is deduced from the compression testing on foam [8].

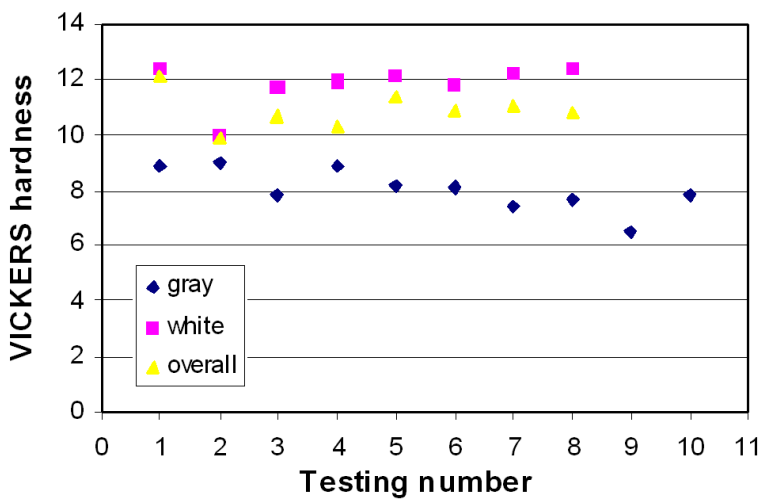

Fig. 9. Vickers pyramid hardness for the lead rich phase, the tin rich phase (load of $0.5 \mathrm{~g}$ ) and hardness for the alloy (under a load of $10 \mathrm{~g}$ ) vs. the test number. 


\subsection{Differential thermal analysis "DTA"}

DTA results for binary alloys for samples obtained at cooling have been related to the solidification path of each alloy. Figure 10 presents a typical thermogram and illustrates the transformations occurring during the cooling for Sn50-Pb alloy. In the cooling curves, obtained with a cooling rate of $5 \mathrm{~K} / \mathrm{min}$, two exothermic signals are observed. They are related to the following transformations:

1. $310^{\circ} \mathrm{C}$, stable solidification, Liq. $\Leftrightarrow \beta$ (lead rich phase),

2. $190^{\circ} \mathrm{C}$, stable eutectic reaction, Liq. $\Leftrightarrow \beta$ (lead rich phase) $+\alpha$ (tin rich phase)

The eutectic reaction Liq. $\Leftrightarrow \quad \beta$ (lead rich phase) $+\alpha$ (tin rich phase) occurs at $190^{\circ} \mathrm{C}$ in this work close to temperatures published in literature.

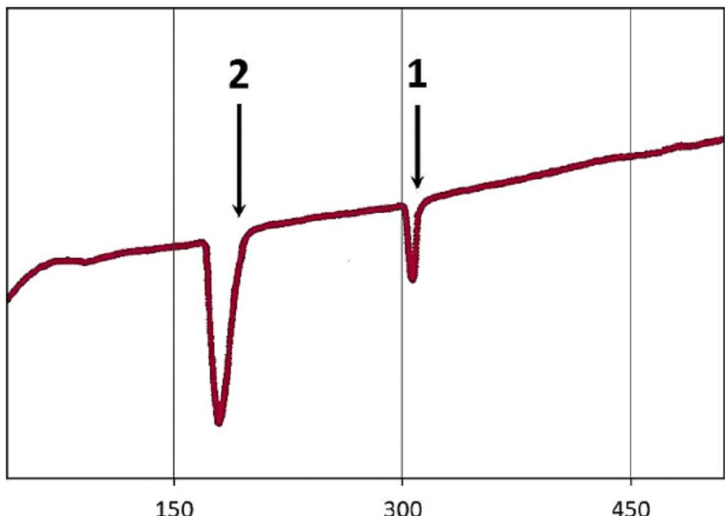

Fig. 10. DTA cooling curve obtained showing the solidification path in $\mathrm{Sn} 50-\mathrm{Pb}$ alloy.

\section{Conclusion}

In this study the mechanical and thermal properties of Sn50-Pb-based metal foam was investigated as a function of pore size and relative densities of the specimens. The relative density significantly influenced the tensile properties of foams: with increasing density the elasticity limit moved to higher values.

\section{References}

[1] C. San Marchi, A. Mortensen, Acta Mater. 9, 3959 (2001).

[2] A. Fazekas, R. Dendievel, L. Salvo, Y. Bréchet, Int. J. Mech. Sci. 44, 2047 (2002).

[3] S. Akiyama, H. Ueno, K. Imagawa, A.A. Kitahara, S. Nagata, K. Morimoto, T. Nishikawa, M. Itoh, 1987, US Patent 4713277.

[4] I. Jin, L.D. Kenny, H. Sang, 1992, US Patent 5112697.

[5] W.W. Ruch, B. Kirkevag, 1991, Patent WO 9101387.

[6] L. Polinski, S. Lipson, H. Markus, Modern Cast. 39, 57 (1961).

[7] S.R.E. Casolco, G. Dominquez, D. Sandoval, J.E. Garay, Mater. Sci. Eng. A 471, 28 (2007).

[8] A. Belhadj, S.-A. Kaoua, M. Azzaz, J.D. Bartout, Y. Bienvenu, Mater. Sci. Eng. A 494, 425 (2008).

[9] G.V. Brook, E.A. Brandes, Smithels Metals Handbook, 7th ed., Butterworths, London 1992.

[10] T.B. Massalski, Binary Phase Diagrams, ASM International, Materials Park, OH 1990.

[11] L.J. Gibson, M.F. Ashby, Cellular Solids, Structure and Properties, 2nd ed., Cambridge University Press, Cambridge, UK 1997.

[12] P.T. Vianco, in: ASM Handbook, Vol. 6, ASM, Materials Park, OH 1993, p. 964.

[13] J.F. Secondé, Ph.D. Thesis, INP, Grenoble 1984. 